\title{
Lingua Franca to Lingua Shrunka: Changing Perspective of Post-Modern Communication through Technology
}

\author{
Preeti Tushar Joshi \\ University of Pune, Maharashtra, India \\ *Corresponding Author: preeti.joshi2001@gmail.com
}

Copyright (C 2014 Horizon Research Publishing All rights reserved.

\begin{abstract}
Technology has revolutionalized modern man's life at the global level including the field of language. The current paper tries to study the impact of modern communication tools on written English language. This is the area where technology has had the biggest impact. Email altered the structure of the letter as a communicative tool. It introduced new etiquette, new conventions, new abbreviations, acronyms such as BFN, FYI, PFA. Mobile phones with SMS have an astonishing impact on lexical and syntactical aspects of language. Language is getting shorter and shorter by the by. Two more points to be considered in this transition are the screen size of the mobile and writing as a time consuming task. Therefore, with fewer efforts if person conveys the same message "why won't he go with this lingua shrunka?" In this type of language, punctuations make words, letters create sentences, and a mere preposition can be a proposition. Even 'emoticons' offering away out of wordiness and creatively solving the problem of being unable to see facial expressions or hear tones of voice in typed correspondence. They provide substitute for words and sentences. To sum up....email, SMS (texting), blogging, twittering, social networking sites tell people write the way they speak less like they used to write. Therefore, language used in modern communication tools is very popular which makes the use of the phonetic part of the language and uses only those words, which are absolutely necessary eliminating redundant words.
\end{abstract}

Keywords Communication Tools, Acronyms, Lexical and Syntactical Aspects, Lingua Shrunka, Emoticons, Phonetic Part of the Language

Theme: Linguistics and Multilingual Studies (Technology Impact and Use of Language)

\section{Introduction}

Man has evolved as the most powerful and capable species on the earth and his power to communicate has had a major contribution in this regard. Language came into being as a means of communication. Initially it was a language of cries and gestures but later on it has gone through tremendous change as per the need of time. Various theorists have discussed evolution of theory of communication through language. To begin with Aristotle's Rhetoric in which he has mentioned that it as an art of discourse, an art that aims to improve the capacity of writers or speakers that attempt to inform, persuade or motivate particular audiences in specific situations. Kenneth Burke's Rhetoric of Communication deals with rhetorical practices of speeches. Lasswell on the other hand develops a model of communication in which he says that an act of communication takes place through the following procedure of answering questions 'who says what, in which channel, to whom, with what effect.' Today we are living in the world of cybernetics according to Colin Cherry. He has shown how communication through words has added beauty of multiple meanings, 'A meaning is not a label tied around the neck of the word or a phrase. It is more like the beauty of complexion which lies altogether in the eyes of its beholder (but changes with the light).'

Watzlawick, Beavin, and Jackson in the Pragmatics of Human Communication define it as a structured system of psychological, social, cognitive and cultural components. The theorists have a common thing to say about communication that has been exactly pinpointed by the German Philosopher and linguist Wilhelm von Humboldt in 1936, 'There can never be a moment of true standstill in language, just as little as in the ceaselessly flaming thought of men. By nature it is a continuous process of development...' On the whole language is a product of the society, for the society and by the society. Linguists must understand the fact that language and society culture change and their changes are interdependent.

\section{Methodology}

The present paper aims at exploring the features of language used in modern communication tools on the basis of the data collected from various sources.

The present paper applies experimental research method for analysing and describing communication taking place through modern communication tools amongst different 
professionals. The samples include SMSes, online chatting and e-mails used for correspondence. Collected samples were scrutinised on the basis of the norms of standard written communication and the present way of casual and precise but very effective and creative use of English amongst youngsters through the tools mentioned above.

Shrivastava and Sharma (1991) comment,

'The shape of English used in India is being determined by perhaps the most influential section of the educated societywriters, journalists, doctors and above all teachers of English in India.' (p.199)

To make this study more representative, messages (SMS) collected from various people of different professions are collected. The proposed research designs to adopt the following methodology.

The primary source of research is the messages collected from different people of different professions like doctors, businessmen, teachers and students, etc.

The secondary source would be various reference books, research articles, and journals related to the present area of study. The collected data will be segregated and applied wherever needed.

The observations in this study are based on the close analysis of limited amount of data and this certainly imposes limitations on the validity. However, the findings made in this study on the basis of the collected examples may be seen as symptomatic of what is likely to be manifested by a large corpus.

The examples cited in this chapter are of the following type:

a. Some examples of messages (SMS, chats and e-mails) are collected from different professionals. Some articles from newspapers and books are studied. The generalizations made in this study are based on the analysis of data from two newspapers - 'The Times of India' and 'The Indian Express' and some books of different writers like Crystal, Gramley and articles by writers like Vinay Kamat.

b. Most of the examples cited are actually used by the people in real context.

c. Some of the examples from the analysis are constructed on the basis of observation and intuition to reveal the patterns actually used by the users of modern communication tools.

\section{Scope and Limitations}

In today's fast and modern life style, modern communication tools have gained wide acceptance. This type of communication is very popular amongst the youth, especially the college going students as it helps them to be in touch with each other instantly with a very minimal cost as compared to other tools.

Furthermore, the business class also uses it very strongly to communicate quick messages to keep the communication link intact and to move faster.

Service providers / companies also make use of text messaging to communicate with its customers to a large extent.

In this study, it is intended to undertake a survey, in which primary sources from all these segments would be contacted to check their usage of SMS, their style and specially created vocabulary.

The study of the language used in SMS is very vast. It can be studied mainly at two levels: Syntactic and Morphological level. For practical purpose, the researcher has selected only vocabulary part used in SMS, which falls under the later one.

The analysis would be based on the collected and segregated data. Term syntax, vocabulary, its use and form in SMS are discussed in detail. The similarities and differences between vocabulary in SMS and other text forms are also analyzed. It is an attempt of the researcher to reveal different features of vocabulary used in SMS.

In the present study, syntactic features of language used in modern communication tools are considered. The focal point is limited to vocabulary and syntax. The features like spellings, form of writing, grammar of vocabulary, process of word formation, borrowing, punctuation, etc are discussed in detail.

\section{Discussion}

English was initially a Queen's language in India but later on it was amalgamated with regional variety of dialects, idiolects, pidgins and Creoles from Indian regional languages. Crystal in his book says that languages are not static but are constantly changing. The latest slang comes and goes. Our own language is subtly but noticeably different from that of our grandparents and the further back we go in time the more remote and incomprehensible the language seems to be. Shakespeare's language is difficult for us, Chaucer's even more so. Should we be bold enough to pursue the writings of King Alfred who lived in $9^{\text {th }}$ century, we will barely understand a word even though he has written in English.

This is leading "to a kind of "World" or "International English", one stripped of its local identifiers, with a core of common vocabulary, grammar, and spelling.' (Burridge and Mulder, 1998:277) The change has been approved by the lovers of the language as a nature's law to change, constancy alone is strange. In a world where humans grow old, tadpoles change into frogs and milk turns into cheese, it would be strange if language alone remained unaltered. As famous Swiss linguist Ferdinand de Saussure noted, 'time changes all things. There is no reason why language should escape this universal law.'

Many linguists have put forth their opinions about the usage of language. Robert Hall Jr. says, "There is no such thing as good and bad (or correct and incorrect, grammatical and ungrammatical, right and wrong) in language. There is no such thing as written language, there is speech and there is writing and of these two, speech is basic in human life and writing is reflection of speech. Changing the writing is not changing the language." (1968:67). It is certain that language 
is ever dynamic and ever changing. Chomsky (1965:232) suggests that neither grammaticality nor acceptability are absolute concepts. There are degrees of grammaticality and acceptability. Language has always been assessed as being door to the culture. The more refined is language, the better cultured man has thought to be. Till date languages and society culture continue to evolve simultaneously, but of all the languages English has come a long way. It got an advantage of its colonial status to get popularized at different corners of the world and every colony coloured it in its own culture. Indian English is one of such examples.

The present paper is a modest attempt to probe into the changes that have come in the language due to advancement of modern communication tools like mobiles with different applications and internet with blog, twitter, and an email. It deals with the journey of English language for communication in Indian context from its initial position of Lingua Franca to today's short but sweet use through Lingua Shrunka. Collins in his dictionary defines Lingua Franca as, 'A language used for communication among people of different mother tongues.' On the other hand Webster defines it as, 'Any language that is widely used as a means of communication among speakers of other languages.' Initially it was regional variety of vernacular languages that crystallized with the British English. Further it moved on as a language of international trade, international travel, satellite broadcasting, the internet, the world press, world stock markets, multinational corporations, science, air traffic control, and many more areas rely to a remarkable extent on English.

Today, technology has revolutionalized modern man's life at the global level including the field of language. Especially the written language is the area where technology has had the biggest impact. Email altered the structure of the letter as a communicative tool. It introduced new etiquette, new conventions, new abbreviations; acronyms such as BFN (bye for now), FYI (for your information), and PFA (please find attachment. Mobile phones with SMS have an astonishing impact on lexical and syntactical aspects of language. Language is getting shorter and shorter by the by. Two more points to be considered in this transition are the screen size of the mobile and writing is a time consuming task. Therefore, with fewer efforts if person conveys the same message "why won't he go with this lingua shrunka?" In this type of language, punctuations make words, letters create sentences, and a mere preposition can be a proposition. When it comes to writing with the help of modern tools of communication, people write the way they speak less like they used to write. Therefore, language used in modern communication tools is very popular which makes the use of the phonetic part of the language and uses only those words/letters, which are absolutely necessary eliminating redundant ones.

English varies, sometimes enormously, depending on such factors as where it is used, who uses it, and how it is used. English in India has changed the apparel of Lingua Franca and adapted to the new Glocal (global + local) attire of lingua shrunka. Along with the various regional varieties like
Hinglish (Hindi+English), Minglish (Marathi+English) and so on and so forth there is a new kind of variety known as 'Younglish (Young+English)' that needs to be noticed. Youngsters are the most creative and destructive force of the society. Let us see an example of how they enhance and shrink, and make and break the age-old usage of English language,

\section{'Is dis da futr of da Eng Ing? \\ , No thank u pleez, \\ v r desi' etc}

It has come true what dada of mass culture, Marshall McLuhan said, 'We become what we behold.' In the era of wireless, we become what we hold. Mobiles with SMS, texting and internet with social networking sites, blogs, twitter has gigantically changed the face of English language. Use of mobile phones is increasing day by day in India and so is the use of text communication on mobile thorough Short Messaging Service (SMS) and more recently through applications like Blackberry Messengers (BBM) and 'whatsapp'. The total mobile subscribers' base in India as on Oct $1^{\text {st }} 2013$ was 875.48 million. Since the past 3-4 years this number is growing with a phenomenal average year-on-year growth rate of more than $40 \%$.

Moreover, as per the latest figures published by the Internet and Mobile Association of India (IAMAI) the number of internet users through mobile handsets is expected to reach 155 million by March 2014. This will give you an idea of scale with which new form and style of text communication is getting used.

But are they ruining the English language? Instead of entering into debate let us look at it as gain is always associated with pain. From the ancient to modern masters of Literary theory and criticism like Aristotle to Derrida and the versatile writers like Shakespeare to Rabindranath Tagore, we have always followed them by their thoughts. Initial resistance to any kind of change has become a routine after some days. Language preferred by the users of modern technology has been accepted today as a new variety of English. The standard publications like the Oxford, the Cambridge have decided to go with the time by incorporating some of the abbreviations and blending of today's generation in their new editions. In the point of view of Younglish users, modern communication tools are the hottest drugs that are more addictive than any mood food. By using the ligua shrunka of modern communication tools, they have nothing to lose but hegemony of grammar's tyranny perhaps.

Let us evaluate this new language usage of modern generation. The English that was found in Wren and Martin has got conspired to make it 'Engleash' (English + leash). Further modern tools of communication have 'unleashed rings and beeps on solitude'. English now is started fading into Younglish. Let us look at the change from old days English to a new post-modern form of a language known as 'fusion' of all subjects in which we have digits, figures, words, signs and symbols and what not! It has definitely triggered our creativity though it has taken us far away from 
technicalities like grammar, syntax, semantics, phonology, and morphological part of language usage. In olden days if we loved sums, we hated sonnets. These days, Maths and English are cohabiting to make messaging sensual. The following example will help to understand making of a new style of communication and breaking off of old style of formal writing. Though the following examples are considered as ungrammatical, they do reflect creativity of today's generation: Younglish:

Boy: $\mathbf{r} \mathbf{u}+$

Girl: i m (.)

Boy: c u@ 7

Girl: i m h\%kd

If we look at it as an art we definitely appreciate the change but if we look at it as a strict grammarian we hate it the most. This language is like practising the art of pointillism. There is a lot if use of exclamations and commas, slashes and dashes. So the words are replaced by those signs. Let us find out the changes that have been noticed in the use of techno-language.

The first aspect to be taken into consideration is the vocabulary or choice of diction preferred by Youngsters. English used by new generation dominated by modern communication tools can be called as 'The General Variety of English'. The new vocabulary of SMS, Email shorthand, the jargon of computers and movies and Hinglish has all changed the structure of English in India. Some of the English words are becoming so common across various sections of society even among the less and uneducated individuals as if these words belong to their routine colloquial language of communication. For example words like 'Sorry', 'Thank You', 'Flat', 'Time', 'System', 'Hello', 'Bye' and so on. You would generally find less educated or uneducated persons from Urban India comfortable saying "Muze Ek Flat Kharidna Hai", "Kitana Time Lagega", "Iska System Chalu Nahi", "Chalta Hu Yar Bye". This is the new culture that has evoked because of the new English in our society.

The second aspect of this variety is the use of 'Brewity (brief+witty)' in it. The concept of this modern language was conceived years before its symbiotic relationship with Modern tools. Shakespeare's dictum, 'Brevity is the soul of life' which Polonius in Hamlet gave is followed by today's youth is still valid. Charles Dickens captured the soul of romance in one line: Barkis is willin. Years, years later Michael Lewis unravelled the plot of his best-selling Liar's Poker in a single stunner: One hand, one million dollars, no tears. These are not SMS messages though they sound like them. As sound bites, they predate the textronic (text+electroic) transformation that is making SMS an extension of mind. This language, text aka SMS, is the latest spice added to the English language. In fact text is officially verb now- to text is to send someone an SMS. True these days sentence is turning lean. Slang is flirting with syntax. Indeed, at the press of few keys, SMS, texting are hooking generations. All we need to do is to activate internet and cell phone service and to say S to SMS we can be a part of
Generation i2u or Tribe SMS. But we should not overlook the fact that change in culture and change in language is interdependent. Language has always been assessed as being the door to culture. Till date Languages and culture continue to evolve simultaneously, but of all the languages English has come a long way. Traugott has positively supported this change as, "The ...... spread of English as a global language has been seen to mark the threshold of the Modern English Period." (Traugott, 1972:162f)

A third type has developed within the medium of e-mail is the 'emoticons'. It is possibly the most original feature of online communication, neatly and creatively solving the problem of being unable to see facial expressions or hear tones of voice in typed correspondence.' (Flexner and Soukhanov 1997:75) An emoticon (the word is itself is a blend of emotion and icon) offers a way out of wordiness. It is a combination of characters (for the most part punctuations marks) which produce a stylized head, always seen from the side and embellished to indicate something about the writer. The best known of these is the smiley, consisting of colon, hyphen, and closing parenthesis, : - ). The new culture of 'emoticons' is also the result of impacting in seconds.

Today's generation is more towards getting everything quick, something that consumes less effort and time. This life style is also getting visible in the way they communicate. Just like Cricket has seen changes from Test Cricket to T20.

More importance is given to basic understanding and all the rules and regulations of languages are kept aside. For example, 'TC' stands for 'Take Care', 'PFA' stands for 'Please find Attachment', Some of the important processes which are involved in language change; especially at the morphological level are abbreviation, acronyms, antonomasia and derivation etc. Noun message is derived into a verb in the language used in the modern communication tools.

The fourth one is of the construction pattern of Younglish. The modern world of media and advertisement has fuelled the new thinking. In this world of ASAP, FYI we do not have time for long sentences nor can we negotiate with long interpretations. With the world being constantly on toes, English has become master language of punch lines. New words like electrifying, commodification have become common. Hybridization, where a convenient combo of words from two different languages is made is getting widely acceptable. With the world being constantly on toes, English has become master language of punch lines. For example, the punch line of last year's Pepsi advertisement campaign 'Oh Yes Abhi!' or the famous ad campaign of Idea Cellular Services using the punch line as 'What an Idea Sirji to name a few.

The fifth aspect is the grammatical changes that have occurred. The world of grammar is following the footsteps of dinosaurs. Punctuation, capitalization, syntax have been altered tremendously. Ten years back when we used to read in newspapers sentences like 'It is a good read' we used to think it is a printing mistake. But today every news channel and every paper writes: 'He did a salman'. There is no 
denying the truth that, today the new English and the new culture are in a state of flux, that is confused mixture in language and culture, wherein BTW is By The Way in email shorthand while it is 'Between' in SMS language. Even LOL can be lots of love or laugh out loudly.

The sixth aspect is of linguistic competence. When it comes to the linguistic competence of this new English then there is no prescriptive grammar, resulting in lots of miscommunication and misunderstandings at times. The linguistic performance varies from individual, place to place, and time to time. Never has any language or any culture been perfect since its inception. They evolve with time. So it can be considered that the new lingo is evolution English language with new morphological, grammatical format so should not be hurried to label it as mistake or ungrammatical. Converting verb into noun or vice versa is regularly used well known method in morphology that is derivation. Even use of words like, Kamala, Champak is examples of 'antonomasia'.

The seventh aspect is very important as it deals with new emerging culture through Younglish. There is no denying that English has been a boon in many ways in India. English is the link language that provides a communicative channel for the Indians belonging to diverse linguistic regions to interact and rather we can say it has helped in binding the Indian Youth as well. Of course the lingua franca is English changing its form into lingua shrunka. This is the result of increased use of modern communication tools.

It does not mean that such kind of communication is always unproblematic. Speculations about the consequences of this for the type of language used have been mooted from various sides. And, indeed a few changes in conventions seem to have entered the scene. Because much of Internet and SMS communication is (still) by keyboard, the importance of literacy, often in English, has been enhanced, but some of the disadvantages of writing have also lead to changes. One of the limitations of the writing is that everything you want to say must, quite literally, be spelled out. Since this is a relatively time-consuming process, modern communicators have eagerly turned to short-cuts. Among these, we can say abbreviations, acronyms, etc.

\section{Results}

The descriptive analysis of collected samples has led us to the following findings. From the above discussion, we can see that English language used in the modern communication tools is different from the language used in other written communication. Being language teachers we cannot be neutral, we need to adapt ourselves to this new language. But before that we have to ascertain the structure of this language. The language used in the modern communication tools is constantly changing. Any language or culture starts with a number of people following the same pattern which then becomes the norm and finally a standard. The standard of this new general variety of English language has to be decided so that there is no semantic gap or error in communication. For that we again need prescriptive rules and its respective grammar. Otherwise everyone shall continue to codify language with not many being able to decode the same way. We are living in a very fast culture hence our pace to form its base has to match accordingly. For all its limitations, language used in modern communication tools is not a spurious concoction, it is a genuine decoction. It is the essence of English, as we want it to be. Time shall test whether it stays and evolves into a standard form or just a passing phase.

The UK and New Zealand have allowed students to use SMS lingo (language) in exams. Indian teachers, scholars are fine with expressing everything in SMS or modern lingo -from lets-brk-up to wl-u-mary -me but language in the classroom should remain sacrosanct. Even a New Zealand party protesting the move put their official statement thus-"Untd Futr is cncernd bout da xeptnce of txt spk $2 \mathrm{~b}$ allwd in ritn xams 4 NCEA. Skoolz $r$ ther 2 eduk $8+$ raze litracy 2 certn standards. (United Future is concerned about the acceptance of text speak to be allowed in written exams for NCEA. Schools are there to educate and raise literacy to certain standards.)

But the language is never without irony, is it? And therein lies a tale!

\section{REFERENCES}

[1] Aitchison, J. (1981), Language Change: Progress or Decay, Fontana, London..

[2] Crystal, D. (1997), English as a Global Language, Cambridge University Press, Cambridge.

[3] Crystal, D. (2001), Language and Modern Communication, Cambridge University Press, Cambridge.

[4] Gokhale, S. B. (1988a), 'Standard Indian English and the Notions of Correctness and Error' in C. Ali and S. Wareing (eds.) Strathclyde Working Papers in Language, Literature and Culture, Volume 1, Number 2, pp. 13-25.

[5] Bhattacharya, M. Changing Structure of English in Contemporary India, ELT Weekly, Vol.3:Issue77. January, 2011.Web.

[6] Kamat, V. (2007), 'Is SMS Ruining The Language?' The Times of India, Pune Times, 14 April, 2007.

[7] Anubha, S. (2007), 'Is Dis Da Futr Of Da Eng Lng?' The Times of India, Pune Times, 16 November, 2007.

[8] Arora, C. (2009), 'Queen's English Gets Short And Sweet!' The Indian Express, Pune Newsline, 16 April, 2009.

[9] http://www.iamai.in/reports1.aspx 